galactic centre and is low within this distance. If we predict the $\gamma$-ray profile assuming that the emissivity in the plane mirrors this synchrotron emissivity but that its scale height is that of the gas, a reasonable fit to the observations is obtained. If the two emissivities are in constant ratio the implication is that $B^{2}$ is proportional to gas density on some suitably large scale in the plane of the Galaxy. Developing instabilities would extend the magnetic field out of the plane and destroy the proportionality there.

Received 2 September; accepted 5 December 1980.

1. Cesarsky, C. J. Ann. N.Y. Acad. Sci. 336, 223 (1979).

2. Paul, J. Cassé, M. \& Cesarsky, C. J., Astrophys, J. 207, 62 (1976).

3. Jäkel, C. E., Nissen, P., Schlickeiser, R., Thielheim, K. O. Proc. 14th int. Cosmic Ray Conf. 12, 4177 (1975).

4. Higdon, J. C. Astrophys. J. 232, 113 (1979).

5. Haslam, C. G. T. et al. Astr. Astrophys. (in the press)

6. Haslam, C. G. T., Salter, C. J., Stoffel, H. \& Wilson, W. E. Astr. Astrophys. Suppl. (in the press).

7. Mayer-Hasselwander, H. A. et al. Ann. N.Y. Acad. Sci. 336, 211 (1980)

8. FichteI, C. E., Kniffen, D. A., Hartman, R. C. \& Thompson, D. J. Proc. 12th ESLAB Symp. (European Space Agency, Frascati, 1977).

9. Hirabayashi, H. Publ. astr. Soc. Jap. 26, $263(1974)$

10. Hermsen, W. thesis, Leiden Univ. (1980).

10. Hermsen, W. thesis, Leiden Univ. (1980).
11. Montmerle, T. Astrophys. J. 231, 95 (1979).

12. Phillipps, S., Kearsey, S., Osborne, J. L., Haslam, C. G. T. \& Stoffel, H. Astr. Astrophys. (in the press).

\section{Laser-radar measurements in southern England of aerosols from Mount St Helens}

\section{Thomas, C. P. Chaloner \& S. K. Bhattacharyya}

SRC Rutherford and Appleton Laboratories, Ditton Park, Slough, Berks SL3 9JX, UK

Material from the eruption of Mount St Helens $\left(46^{\circ} \mathrm{N}, 122^{\circ} \mathrm{W}\right)$ has been detected at lower stratospheric heights using a laserradar system at Winkfield $\left(51^{\circ} \mathrm{N}, 1^{\circ} \mathrm{W}\right)$. The observation of a distinct layer of $\sim 1 \mathrm{~km}$ thickness near $15.5 \mathrm{~km}$ altitude for several days in early June is consistent with the west-east transport of material from above the eruption site expected at this height and also indicates a significant northward spread of the material. In late July less pronounced layers were observed at $17-18 \mathrm{~km}$ and $22 \mathrm{~km}$ at which level the direction of motion is less certain.

The laser incorporated in the radar system operated near a wavelength of $0.6 \mu \mathrm{m}$ and produced $1 \mu \mathrm{s}$ pulses at a repetition frequency of $1 \mathrm{~s}^{-1}$. The receiver included a $0.8-\mathrm{m}$ diameter newtonian telescope and operated in a photon-counting mode, the return signals being recorded in channels corresponding to $1 \mathrm{~km}$ height intervals. The inclusion of a neutral density filter in the receiver and the restriction of the laser energy to a very low value ( $<20 \mathrm{~mJ}$ ) ensured that the photomultiplier was not overloaded by returns from low altitudes.

The results obtained near the end of May and during June are presented in Fig. 1. These show the variations with height of the range-corrected backscattered signal and standard error for $\sim 1 \mathrm{~h}$ of observations on each of four nights. In each case the corresponding height variation expected for the Rayleighscattered signal is shown, as derived from molecular densities obtained from radiosonde data for Crawley $\left(51^{\circ} \mathrm{N}, 0^{\circ} \mathrm{W}\right)$ provided by the Meteorological Office, Bracknell, and fitted to the observations at the lower heights. The tropopause heights indicated were from the same data. The deviations from the Rayleigh scattering results on 27 May are consistent with other measurements at Winkfield before the eruption ${ }^{1}$. Note the strong scattering from heights of $\sim 15.5 \mathrm{~km}$ during the nights of 6 and 7 June; this feature was observed consistently between 4

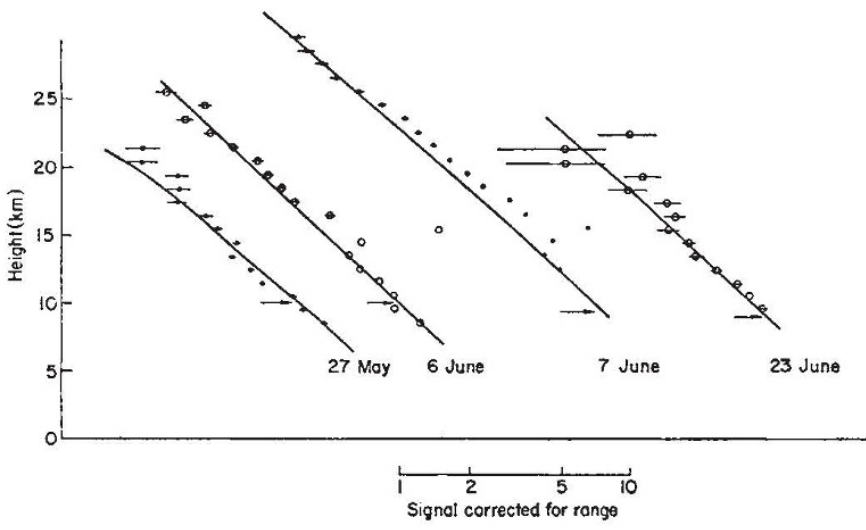

Fig. 1 Variations with height of the range-corrected signals from soundings at vertical incidence during four nights. The smooth curves represent the corresponding variations expected for Rayleigh scattering as computed for molecular densities derived from radiosonde measurements which also provided the tropopause heights denoted by arrows.

and 9 June, adverse weather conditions interfering with measurements on either side of these nights. In addition, small enhancements are shown over the height range $16-24 \mathrm{~km}$ on the 7 June. Balloon-borne observations ${ }^{2}$ of scattered sunlight in southern France on 5 June also showed the presence of an enhanced aerosol layer at a height near $15.5 \mathrm{~km}$. The presence in the eastern US on 22 May of layers of material between 12 and $16 \mathrm{~km}$ from the Mount St Helens eruption was recorded with the NASA Langley airborne laser radar system ${ }^{3}$. Furthermore, the absence of anomalous scattering at Winkfield on 27 May was consistent with the location of the $14-16 \mathrm{~km}$ material at $\sim 30^{\circ} \mathrm{W}$, as observed ${ }^{3}$ with the satellite-borne Stratospheric Aerosol and Gas Experiment (SAGE). As indicated in Fig. 1, no major scattering was observed at Winkfield during the second half of June.

The approximate arrival date, relatively short duration and the location near $15.5 \mathrm{~km}$ of the layer observed at Winkfield are consistent with the transport of the layers observed previously in the eastern US by the west-east winds expected at these levels during May and June ${ }^{4}$. From an examination of the mean wind for the 100 mbar level, as derived by the Meteorological Office from radiosonde data, it is considered that a significant spread of the material towards the north must also have occurred. Unusual twilight effects following previous volcanic eruptions ${ }^{5,6}$ showed that the dust injected can spread over very large areas within about 2 months of the events. Furthermore, balloonsonde ${ }^{7}$ and laser-radar observations ${ }^{8,9}$ revealed that the maximum enhancements of material extended over a considerable part of the $15-20 \mathrm{~km}$ altitude range, and continued for many months after the eruptions. Small enhancements in scattering have been observed from levels near 18 and $22 \mathrm{~km}$ during nights in the period 21-25 July, the only observable nights during that month.

We thank the Meteorological Office, Bracknell, for radiosonde data and information on winds at the $100 \mathrm{mbar}$ level.

Received 26 September; accepted 17 December 1980

1. Gibson, A. J., Thomas, L. \& Bhattacharyya, S. K. J. atmos. terr. Phys. 39, 657-660 (1977). 2. Ackerman, M., Lippens, C. \& Lechevallier, M. Nature 287, 614-615 (1980).

3. NASA Upper Atmos. Prog. Bull. No. 80.3 (1980).

4. Newell, R. E., Kidson, J. W., Vincent, D. G. \& Boer, G. J. The General Circulation of the Tropical Atmosphere Vol. 1 (MIT Press, 1972).

5. Volz, F. E., Tellus, 17, 513-515 (1965).

6. Volz, F. E. Science 189, 48-50 (1975).

7. Hofmann, D. J. \& Rosen, J. M. J. geophys. Res. 82, 1435-1440 (1977).

8. Grams, G. \& Fiocco, G. J. geophys. Res. 72, 3523-3542 (1967).

9. McCormick, M. P., Swissier, T. J., Chu, W. P. \& Fuller, W. H. I. atmos. Sci. 35, 1298-1303 (1976). 